University of Wollongong

Research Online

Australian Institute for Innovative Materials -

Papers

Australian Institute for Innovative Materials

$1-1-2019$

\title{
Ultrasonic spray deposition of TiO2 electron transport layers for reproducible and high efficiency hybrid perovskite solar cells
}

Jingsong Sun

Monash University

Alexander Pascoe

Monash University

Steffen Meyer

Monash University

Qijie Wu

University of Wollongong, qw988@uowmail.edu.au

Enrico Della Gaspera

Royal Melbourne Institute of Technology

See next page for additional authors

Follow this and additional works at: https://ro.uow.edu.au/aiimpapers

Part of the Engineering Commons, and the Physical Sciences and Mathematics Commons

Research Online is the open access institutional repository for the University of Wollongong. For further information contact the UOW Library: research-pubs@uow.edu.au 


\title{
Ultrasonic spray deposition of TiO2 electron transport layers for reproducible and high efficiency hybrid perovskite solar cells
}

\begin{abstract}
The fabrication of high efficiency perovskite solar cells at larger scales will rely on the optimized deposition conditions of every layer using scalable methodologies. Most current perovskite devices that employ the archetypal TiO2 hole blocking layer utilise a simple air-brush approach. This approach is not scalable as it results in significant layer inhomogeneity across larger devices areas. To overcome this inherent limitation, in this work we use ultrasonic spray deposition as an alternative approach for the TiO2 deposition. Focusing on identical reaction chemistries as for air-brush, namely bis(isopropoxide)bis(acetylacetonate) titanium (IV) based solutions, we find that under optimized conditions smooth TiO2 layers can be readily deposited over scalable areas on fluorine doped tin oxide. Using these layers at electron transport layers within diodes and perovskite solar cell devices, we develop effective benchmarks that predict the effectiveness of the underlying charge transport layer. This enables for the standardisation of the electron transport properties within any batch of solar cells, thus providing a readily accessible pathway towards enhancing reproducibility of fabricated devices. Under these optimized conditions, methylammonium lead halide photovoltaic devices readily possessing efficiencies of $>16 \%$ are achieved. Importantly, the mean batch efficiency of devices fabricated using the ultrasonic spray deposition method is significantly improved and the standard deviation is drastically narrowed. The deposition of an additional meso-porous layer is found to lead to further improvements for both of these parameters.
\end{abstract}

\section{Keywords}

spray, deposition, tio2, electron, transport, layers, ultrasonic, reproducible, cells, high, efficiency, hybrid, perovskite, solar

Disciplines

Engineering | Physical Sciences and Mathematics

\section{Publication Details}

Sun, J., Pascoe, A. R., Meyer, S., Wu, Q., Della Gaspera, E., Raga, S. R., Zhang, T., Nattestad, A., Bach, U., Cheng, Y. \& Jasieniak, J. J. (2019). Ultrasonic spray deposition of TiO2 electron transport layers for reproducible and high efficiency hybrid perovskite solar cells. Solar Energy, 188 697-705.

\section{Authors}

Jingsong Sun, Alexander Pascoe, Steffen Meyer, Qijie Wu, Enrico Della Gaspera, Sonia Raga, Tian Zhang, Andrew Nattestad, Udo Bach, Yi-Bing Cheng, and Jacek Jasieniak 


\section{Ultrasonic Spray Deposition of $\mathrm{TiO}_{2}$ Electron}

\section{Transport Layers for High Efficiency Hybrid}

\section{Perovskite Solar Cells}

Jingsong Sun ${ }^{\not, 1}$, Alexander R. Pascoe ${ }^{\sharp, 1}$, Steffen Meyer ${ }^{1}$, Qijie Wu² ${ }^{2}$ Enrico Della Gaspera ${ }^{3}$,

Sonia R. Raga ${ }^{4}$, Tian Zhang ${ }^{4}$, Andrew Nattestad ${ }^{2}$, Udo Bach ${ }^{4}$, Yi-Bing Cheng ${ }^{5}$, and Jacek J.

Jasieniak*1 $^{*}$

${ }^{1}$ ARC Centre of Excellence in Exciton Science, Department of Materials Science and Engineering, Monash University, Clayton, Victoria 3800, Australia

2 Intelligent Polymer Research Institute (IPRI), Australian Institute for Innovative Materials (AIIM), University of Wollongong, NSW 2522, Australia

${ }^{3}$ Applied Sciences, RMIT University, Melbourne, Victoria 3000, Australia

${ }^{4}$ ARC Centre of Excellence in Exciton Science, Department of Chemical Engineering, Monash University, Clayton, Victoria 3800, Australia

${ }^{5}$ State Key Laboratory of Advanced Technology for Materials Synthesis and Processing, Wuhan University of Technology, Wuhan 430070, China

Keywords: Titania, Spray-Deposition Electron Transport Layer, Perovskite, Solar Cell. 


\section{Abstract}

The fabrication of high efficiency perovskite solar cells at larger scales will rely on the optimized deposition conditions of every layer using scalable methodologies. Most current perovskite devices that employ the archetypal $\mathrm{TiO}_{2}$ hole blocking layer utilise a simple air-brush approach. This approach is not scalable as it results in significant layer inhomogeneity across larger devices areas. To overcome this inherent limitation, in this work we use ultrasonic spray deposition as an alternative approach for the $\mathrm{TiO}_{2}$ deposition. Focusing on identical reaction chemistries as for airbrush, namely bis(isopropoxide)-bis(acetylacetonate) titanium (IV) based solutions, we find that under optimized conditions smooth $\mathrm{TiO}_{2}$ layers can be readily deposited over scalable areas on fluorine doped tin oxide. These are found to serve as highly effective blocking layers, with photovoltaic devices readily possessing highest efficiencies of $>16 \%$. Importantly, the mean batch efficiency of devices fabricated using the ultrasonic spray deposition method is significantly improved and the standard deviation is drastically narrowed. The deposition of an additional mesoporous layers is found to lead to further improvements for both of these parameters.

\section{Introduction}

Hybrid metal halide perovskites have rapidly emerged as a promising material for use in photovoltaics owing to their ease of processing and excellent optoelectronic properties. ${ }^{1}$ Leveraging heavily from gradual advances in dye-sensitised, organic and thin-film inorganic solar cell configurations, ${ }^{2}$ perovskite solar cell (PSC) efficiencies have improved at an unprecedented rate, increasing from an efficiency of only $3.8 \%$ in 2009 , as reported by Kojima et al., ${ }^{3}$ to values 
that already exceed $22 \%$ for lab-scale devices. ${ }^{4}$ This efficiency rivals that of mature solar cells, such as multicrystaline silicon (mc-Si), cadmium telluride (CdTe) and copper-indium-galliumselenide (CIGS) technologies. While PSC devices are still considered an early-stage technology that is yet to identify a relevant market, one of the chief attributes boasted by PSCs is the solutionbased methods commonly used during device fabrication. This attribute affords the potential for mass production, which provides perovskite-based cells with an innate advantage over more established technologies. Nevertheless, PSCs require considerable challenges to be resolved around stability, toxicity and scalability before the technology can be considered as a viable alternative. Important progress has been made to address concerns of device stability ${ }^{5}$ and toxicity, ${ }^{6}$ which are prolific fields in their own right. Here, we focus on addressing a key processing challenge that impacts reproducibility and scalability of PSCs - the deposition of a high quality electron transport layer.

Electron and hole transport layers in PSCs are fundamental towards achieving high efficiency devices as they selectively block holes and electrons, respectively, to reduce interfacial recombination at the electrode interfaces. This has been demonstrated for all high efficiency planar, ${ }^{7-8}$ meso-porous ${ }^{9-11}$ and sensitized ${ }^{12}$ PSC architectures. Within their "normal superstrate" device configuration, that being where the electron transporting layer (ETL) is deposited on the transparent conductive electrode and the hole transporting layer (HTL) is deposited on the perovskite, almost ubiquitously $\mathrm{TiO}_{2}$ has been used as the ETL and doped Spiro-OMeTAD (2,2',7,7'-tetrakis( $N, N$-di- $p$-meth-oxyphenylamine)-9,9-spirobifluorene) as the HTL. Both of these layers have origins in dye-sensitized solar cells (DSSCs). ${ }^{13}$ The selection of the SpiroOMeTAD is largely based on its ease of deposition through a low-temperature solution-coating process. Meanwhile, $\mathrm{TiO}_{2}$ remains the archetypal material owing to its high chemical stability, 
high optical bandgap of $3.2 \mathrm{eV}$ and appropriate conduction band energy of $-4.2 \mathrm{eV}$ vs. vacuum for minimizing voltage losses.

$\mathrm{TiO}_{2}$ deposition has been demonstrated using spin coating, ${ }^{9,} 14$ atomic-layer deposition, ${ }^{15-16}$ spray pyrolysis, ${ }^{11,17-18}$ electrodeposition, ${ }^{19-20}$ sputtering ${ }^{21}$ and thermal oxidation. ${ }^{22-23}$ Of these, spray deposition is the most commonly employed approach owing to its simplicity. It involves the deposition of a suitable titanium complex, such as titanium (IV) bis(isopropoxide)bis(acetylacetonate) $\left(\mathrm{Ti}(\mathrm{acac})_{2} \mathrm{OiPr}_{2}\right)$ dissolved in isopropanol, onto a heated substrate at $\sim 500^{\circ} \mathrm{C}$, which induces its thermal decomposition to form $\mathrm{TiO}_{2}{ }^{24}$ This processing temperature also facilitates crystallization of the $\mathrm{TiO}_{2}$ into the anatase phase, which provides reduced structural defects and improved electron mobilities compared to its low-temperature processed amorphous state. $^{25-26}$

Conventionally, the spray deposition of $\mathrm{TiO}_{2}$ for use as a blocking layer in solar cells has been carried out using an airbrush spray technique. ${ }^{27}$ This form of "pressurized" spray, relies on a high pressure carrier gas to atomise a liquid flowing through a nozzle. The particle diameters emerging from these systems and their size distribution are related to the nozzle geometry, the physical properties of the liquid, its flow rate, the air pressure and distance between the nozzle and the substrate that is being coated. ${ }^{28}$ Typical median droplet sizes of $>50 \mu \mathrm{m}$ are common, albeit with very broad droplet size distributions due to the inherent atomization process. Importantly, the droplets are carried to the substrate within the gas stream at pressures of 100's $\mathrm{kPa}$, which causes them to have very high impact velocities with the substrate (10-100's $\mathrm{m} / \mathrm{s})$. Practically, this is beneficial from the point of view of reducing evaporation rates of volatile droplets during the deposition process, particularly when depositing on heated substrates. However, the large distribution in droplet size can make coatings inhomogeneous and the high pressures cause 
significant overspray, which necessitates high efficiency exhaust systems and increases material waste.

For these reasons, ultrasonic spray deposition systems have started to be harnessed in many applications that require homogeneous thin film coatings, such as protective coatings for steel, ${ }^{29}$ transparent electrodes, ${ }^{30}$ and even perovskite solar cells. ${ }^{31}$ Ultrasonic nozzles use a tip vibrating at a frequency $f$ to nebulize a liquid stream into a mist of droplets. The median droplet size in this case is proportional to $\mathrm{f}^{-2 / 3}$, which for typical frequencies of $20-100 \mathrm{kHz}$ gives median droplets of size $\sim 20-100 \mu \mathrm{m} .{ }^{32}$ Importantly, these droplets have a narrower size distribution and 10-100 times lower impact velocities as compared to the airbrush spray approach. The lower size distributions can enable more homogeneous coatings to be prepared, which is a very lucrative aspect for the use of ultrasonic systems in thin film coatings.

In this work, we compare the airbrush and ultrasonic deposition of $\mathrm{TiO}_{2} \mathrm{ETLs}$ for use in methyl ammonium lead iodide $\left(\mathrm{MAPbI}_{3}\right) \mathrm{PSCs}$. It is found that ultrasonic deposition results in superior device performance under optimized conditions and, more importantly, yield a significant improvement in terms of device reproducibility.

\section{Materials and experimental details}

$\mathrm{TiO}_{2}$ blocking layer deposition and characterization. Unless otherwise stated, all materials were purchased from either Sigma-Aldrich or Alfa Aesar, and used as received. The home-built spray system comprised a Sono-Tek $120 \mathrm{kHz}$ Accumist ultrasonic spray shaping nozzle mounted to a 3-axis gantry robot, a Sonotek Selectaspray cabinet with a generator sequence controller, and a syringe pump liquid delivery system. Fluorine doped tine oxide (FTO)/glass substrates were 
cleaned using a three stage sonication process in hellmanex, water and ethanol. The dense $\mathrm{TiO}_{2}$ blocking layer was formed by the spray pyrolysis of a bis(isopropoxide)bis(acetylacetonate)titanium(IV) (TAA) solution at $500{ }^{\circ} \mathrm{C}$. This solution was formed by diluting TAA in isopropanol $(1: 19 \mathrm{vol})$. The sprayed samples were annealing for $10 \mathrm{mins}$ at $500{ }^{\circ} \mathrm{C}$ in air after the completion of the spray cycle, before being cooled down to room temperature. For the mesoporous devices, an $18 \mathrm{~nm} \mathrm{TiO}_{2}$ nanoparticle paste (JGC-C\&C) was diluted in ethanol (1:8 vol) prior to spin-coating on the dense $\mathrm{TiO}_{2}$ blocking layer at $8000 \mathrm{rpm}$ for $40 \mathrm{~s}$ in air and then annealed at $500{ }^{\circ} \mathrm{C}$ for 30 mins.

UV-vis spectroscopy was performed using a PerkinElmer Lambda 950 UV/VIS/NIR spectrophometer. Ellipsometric measurements were carried out on J.A. Woollam M-2000DI Spectroscopic ellipsometer with $\mathrm{TiO}_{2}$ samples being deposited on polished silicon wafers with a natural oxide layer. Atomic Force Microscopy (AFM) measurements were performed on a Dimension Icon (Veeco).

Diode fabrication and characterization. Spiro-OMeTAD $\left(2,2^{\prime}, 7,7^{\prime}\right.$-tetrakis $(N, N$-di- $p$-methoxyphenylamine)-9,9-spirobifluorene) was purchased from Luminescence Technology Corp. The spiro-OMeTAD solution was formed by mixing $40 \mathrm{mg}$ of spiro-OMeTAD in $500 \mu \mathrm{L}$ of chlorobenzene, with $7.5 \mu \mathrm{L}$ lithium bis(trifluoromethylsulphonyl)imide in acetonitrile (500 mg $\mathrm{mL}^{-1}$ ) and $16.88 \mu \mathrm{L}$ 4-tert-butylpyridine as additives. This spiro-OMeTAD solution was spincoated on the dense $\mathrm{TiO}_{2}$ blocking layer at $3000 \mathrm{rpm}$ for $30 \mathrm{~s}$. An $80 \mathrm{~nm}$ gold layer was then evaporated onto the devices. The current-voltage response of the diodes were measured with a continuously increased voltage from 0 to $1.5 \mathrm{~V}$ in the dark using a Zahner Zennium electrochemical workstation (ECW IM6). 
Solar cell fabrication and characterization. Fabrication of solar cell devices was carried out in a $\mathrm{N}_{2}$ filled glovebox. The perovskite precursor solution was formed by mixing stoichiometric amounts of $\mathrm{CH}_{3} \mathrm{NH}_{3} \mathrm{I}$ and $\mathrm{PbI}_{2}$ in a combination of dimethyl sulfoxide (DMSO) and $\mathrm{N}$-methyl-2pyrrolidone (NMP) $(7: 3 \mathrm{vol})$ to form a $(46 \mathrm{wt} \%)$ concentration solution. $30 \mu \mathrm{L}$ of the perovskite precursor solution was applied to the surface of the substrate prior to spin-coating. The films were spin-coated using a two-stage process: $1000 \mathrm{rpm}$ for $5 \mathrm{~s}$ using an acceleration of $200 \mathrm{rpm} / \mathrm{s}$, then $6000 \mathrm{rpm}$ for $50 \mathrm{~s}$ using an acceleration of $6000 \mathrm{rpm} / \mathrm{s}$. A nitrogen gas flow was introduced after $20 \mathrm{~s}$ of the second spin-coating step and sustained for a further $20 \mathrm{~s}$. The perovskite films were then annealed on a hot-plate at $100{ }^{\circ} \mathrm{C}$ for a duration of 10 mins. A spiro-OMeTAD solution was spin-coated on the perovskite film at $3000 \mathrm{rpm}$ for $30 \mathrm{~s}$, the same as that deposited on the diode devices. An $80 \mathrm{~nm}$ gold layer was then evaporated onto the devices. Current-voltage characterization was performed using a solar simulator (Oriel) fitted with a filtered $1000 \mathrm{~W}$ xenon lamp to replicate AM1.5, $1 \mathrm{~kW} / \mathrm{m}^{2}$ conditions. The illumination of the light source was calibrated using a silicon reference cell (Peccell Technologies) with a color filter to minimize the spectral mismatch between the calibration diode and the perovskite solar cell. The J-V response was recorded using a Keithley 2400 source meter. The solar cells were masked with a non-reflective aperture of $0.16 \mathrm{~cm}^{2}$ that defined the active area of the device. Impedance spectroscopy measurements were performed under 1 sun illumination using a white LED powered by a PP210 potentiostat. A Zahner Zennium electrochemical workstation ECW IM6 was used as a frequency response analyzer. 


\section{Results and discussion}

The thickness of $\mathrm{TiO}_{2}$ films deposited through the spray deposition of TAA show a linearly increasing relationship with greater concentration of the precursor and the number spray cycles. ${ }^{33}$ However, the resulting structural, optical and electronic properties of the sprayed $\mathrm{TiO}_{2}$ films can vary significantly owing to the large number of experimental variables, such as deposition temperature, rate, spray distance and pattern, gas pressure, etc. In this work we have undertaken this optimization process using the conventionally used TAA: isopropanol solution as a drop-in replacement within an ultrasonic spray deposition system to coat $10 \times 10 \mathrm{~cm}^{2} \mathrm{FTO} /$ glass substrates with $\mathrm{TiO}_{2}$ at $500{ }^{\circ} \mathrm{C}$. Towards this goal, we have investigated myriad of spray parameters within the defined spray pattern shown in Figure 1a. We have defined a single spray cycle as the completed deposition across all four offset spray trajectories (labelled in Figure 1a as 1-4). The optimized conditions at a flow rate of $0.5 \mathrm{~mL} /$ minute with a nozzle velocity of $100 \mathrm{~mm} / \mathrm{s}$ were found to be: length $=12 \mathrm{~cm}$, line spacing $(\mathrm{dW})=1.5 \mathrm{~cm}$, height $=13.5 \mathrm{~cm}$, and nozzle power $=$ $1.5 \mathrm{~W}$. The shaping pressure was controlled between $10-200 \mathrm{kPa}$, with the later being preferred for this particular spray nozzle (vide infra).

Figure $1 \mathrm{~b}, \mathrm{c}$ show the digital photographs of $\mathrm{TiO}_{2}$ film sprayed on a silicon wafer using a typical hand nebuliser at $\sim 350 \mathrm{kPa}$ and our ultrasonic spray system at a shaping pressure of $\sim 200 \mathrm{kPa}$, respectively. For both samples, the spray nozzle was fixed at $13.5 \mathrm{~cm}$ above the substrates and 6 $\mathrm{mL}$ of spray precursor solution was used to do the coating. Ellipsometric mapping of these samples, as measured over $0.4 \times 0.4 \mathrm{~cm}^{2}$ areas, are shown in Figure 1d,e, respectively. It is evident from both the optical images and ellipsometric mapping that the ultrasonic process facilitates $\mathrm{TiO}_{2}$ 
film deposition of an enhanced homogeneity, particularly at the $\mathrm{mm}$ scale. Analysing the ellipsometric maps more closely shows that the $\mathrm{TiO}_{2}$ deposited by the hand nebulizer results in a mean thickness deviation of up to $\pm 15 \%$, while for the ultrasonic process it was $< \pm 5 \%$. This is clear evidence of the superior coating properties offered by the ultrasonic deposition process, and is directly related to the improved droplet distribution.

In addition to homogeneity, the thickness of the $\mathrm{TiO}_{2}$ needs to be precisely controlled to ensure optimised charge blocking layer characteristics. For simplicity, from hereon we define the $\mathrm{TiO}_{2}$ layers deposited on the original FTO coated glass at different cycles as $T_{x}$, where $x$ denotes the number of $\mathrm{TiO}_{2}$ deposition cycles. The thickness ( $\mathrm{t}$ ) of these layers was measured by depositing reference samples on a silicon wafer substrate with a native oxide layer and then using spectroscopic ellipsometry (Figure S1). This approach was chosen because attempts to measure the thickness directly on FTO glass through SEM was deemed inconclusive due to a low contrast between the $\mathrm{FTO}$ and $\mathrm{TiO}_{2}$ layers (Figure S2). From these measurements the functional correlation between $T_{x}$ and $t$ under the above deposition conditions was determined to be $t(n m)=5.9 T_{x}$.

The effectiveness of $\mathrm{TiO}_{2}$ as a blocking layer depends on its hole blocking, electron collection and shunting properties. To analyse the effectiveness of these processes, Au/Spiro-OMeTAD $/ \mathrm{TiO}_{2} / \mathrm{FTO}$ diodes were fabricated using different thicknesses of ultrasonically sprayed $\mathrm{TiO}_{2}$. The corresponding $\mathrm{J}-\mathrm{V}$ curves of these diodes are shown in Figure 2a. For completeness we have also included the J-V curve of Au/Spiro-OMeTAD/FTO structure, even though this is not a diode. Consistent with the standard Schockley one-diode formalism, three regimes can be clearly identified: (i) at low voltages $(<\sim 0.3 \mathrm{~V})$ the devices exhibit Ohmic behavior due to residual shunting, (ii) at intermediate voltages a clear turn-on behavior is seen, which is characteristics of the junction ideality factor, temperature and saturation current, and (iii) at higher voltages the 
current saturates to series resistance limits. The extracted parameters from fits of the diodes to the Schockley diode formalism are included in Table 1 . The ideality factors show a slight variation across the samples, with a general trend of being at $\sim 3$. This suggests that for all the diodes the carrier recombination is likely to be interface or deep-level defect limited. ${ }^{35-36}$ These trends cannot be reliably compared to solar cells because the interfaces and dominant charge transport mechanisms in such devices are entirely different compared to these diodes. We note that the series resistances extracted here are evidently limited by the electrodes and the rectifying junction, and not reflective of the $\mathrm{TiO}_{2}$ layers, which should have seen progressive increase with increasing $\mathrm{T}_{\mathrm{x}}$. A comparison between the shunt resistances provides the most direct measure of the $\mathrm{TiO}_{2}$ homogeneity and effectiveness as a charge blocking interface, although it is hard to determine what an appropriate value should be without a qualitative comparison to a complete solar cell. Such a qualitative comparison has been made by Peng and co-workers for dye-sensitised solar cells by simply considering the currents at $0.4 \mathrm{~V}$ and $0.8 \mathrm{~V}$ for identical diodes made here, but using hand-spray approach for the $\mathrm{TiO}_{2}$. Those values are plotted in Figure 2b, with the authors finding a current density of $0.01 \mathrm{~mA} \mathrm{~cm}{ }^{-2}\left(0.1 \mathrm{~mA} \mathrm{~cm}^{-2}\right)$ at $0.4 \mathrm{~V}(0.8 \mathrm{~V})$ being sufficiently low to yield good blocking properties. We include the equivalent current densities from our diodes for comparison in this figure. It can be observed that the required current densities are achieved at $\mathrm{T}_{2}$, which is equivalent to only $12 \mathrm{~nm}$. This represents a $\mathrm{TiO}_{2}$ film that is $80 \%$ thinner than those reported by Peng and co-workers, indicating a higher quality deposition process using the ultrasonic method. Further inspection of the diodes fits indicates that a progressive reduction in $\mathrm{J}_{0}$ parameter is observed with increasing $\mathrm{T}_{\mathrm{x}}$. This should yield a greater turn-on voltage and, subsequently, higher open circuit voltages in functional solar cells. 
To validate these charge blocking properties, planar $\mathrm{MAPbI}_{3} \mathrm{PSCs}$ were fabricated using the $\mathrm{TiO}_{2}$ films as ETLs ( Figure 3a). The resulting photovoltaic parameters are summarized in Figure 3b. These show comparable median open circuit voltages $\left(\mathrm{V}_{\text {oc }}\right)$ of $\sim 1050 \mathrm{mV}$ and FFs of $\sim 0.72$ across all $\mathrm{T}_{\mathrm{x}}$. This expected trend arises due to the similar interface chemistry between the $\mathrm{TiO}_{2}$ and perovskite layers. Of all the parameters, the short-circuit current density $\left(\mathrm{J}_{\mathrm{sc}}\right)$ shows the largest deviation with a peak value at $\mathrm{T}_{4}$ of $22.4 \mathrm{~mA} \mathrm{~cm}^{-2}$. A progressive reduction is observed at higher $T_{x}$ and at $T_{2}$. This trend can be partly understood from the diode measurements, which show that $T_{4}$ has a 20 -fold greater shunt resistance than $T_{2}$. Within the device, for the $T_{2}$ sample, a low $R_{s h}$ would result in a higher hole surface recombination at the FTO, yielding the lower photocurrent. Meanwhile, at the higher $T_{x}$, an enhancement of the electron recombination is expected due to an accumulation of electrons at the interface within the perovskite arising from the poor electron transport properties of $\mathrm{TiO}_{2}{ }^{34}$ These factors result in the PSCs with $\mathrm{T}_{4}$ posssessing the most optimal hole blocking and electron transport properties, yielding the highest PCEs. Notably, this correlation allows us to identify that a shunt resistance of $\sim 75 \mathrm{k} \Omega \mathrm{cm}^{2}$ for a $\mathrm{FTO} / \mathrm{TiO}_{2} / \mathrm{Spiro}$ OMeTAD/Au diode provides a good benchmark for achieving good blocking layer properties in functional solar cells.

To further investigate the performance variation of these devices, electrochemical impedance spectroscopy (EIS) measurements were conducted under illumination. Figure 4a shows the Nyquist plots for the perovskite device with $\mathrm{T}_{\mathrm{x}}$ ETLs at $0.8 \mathrm{~V}$ bias under the 1 sun illumination. The equivalent circuit used for fitting the EIS data is shown in Figure 4b. It consists of a recombination resistance $\left(\mathrm{R}_{\mathrm{Rec}}\right)$ component, a constant phase element $(\mathrm{CPE})$ element and a series resistance $\left(R_{s}\right)$ contribution. We find that the series resistances of $T_{2}$ to $T_{6}$ devices are comparable at $\sim 1.9 \Omega \mathrm{cm}^{2}$, but that the $\mathrm{T}_{10}$ device shows an increased series resistance of $2.8 \Omega \mathrm{cm}^{2}$ (see Figure 
4a (inset)) This confirms that the $\mathrm{TiO}_{2}$ layer is indeed having an impact on the total series resistance, but it is signficant only at the larger thicknesses. In Figure $4 c$ we show the $\mathrm{R}_{\text {Rec }}$ versus applied voltage. The recombination resistance shows an increase from $T_{2}$ to $T_{4}$ devices and then subsequently drops for the $\mathrm{T}_{10}$ device. As higher $\mathrm{R}_{\mathrm{Rec}}$ correlates to reduced carrier recombination within a device, ${ }^{37}$ the above results confirm that the $\mathrm{T}_{4}$ devices provide a $\mathrm{TiO}_{2}$-perovskite interface with the most favourable charge extraction characteristics as well as optimum blocking of the FTO recombination pathways. We summarize the above findings through a schematic of the proposed carrier extraction and recombination mechanisms at the $\mathrm{TiO}_{2}$-perovskite for different $\mathrm{T}_{\mathrm{x}}$ in Figure $4 d$.

Noting that PSC exhibit the hysteresis, in Figure 5a we show typical forward and reverse J-V curves of planar PSC using $\mathrm{T}_{4}$. The reverse scan shows a PCE of $17.5 \%$, with $\mathrm{V}_{\text {oc }}=1048 \mathrm{mV}$, $\mathrm{J}_{\mathrm{sc}}=23.2 \mathrm{~mA} \mathrm{~cm}^{-2}$ and $\mathrm{FF}=0.72$, while the forward scan shows a decrease in $\mathrm{FF}$ to 0.55 , which leads to a lower PCE of $13.1 \%$. The steady-state output of this PSC was measured using a voltage of $850 \mathrm{mV}$ at maximum power output for $300 \mathrm{~s}$, where the efficiency stabilized to $\sim 16.3 \%$, as shown in Figure $5 b$.

The above PSCs were fabricated using $\mathrm{TiO}_{2}$ at a nozzle shaping higher pressure of $200 \mathrm{kPa}$; however, as we now show, this high gas pressure is a very important factor for achieving such high efficiency PSCs. In Figure 6a,b, digital images of $\mathrm{T}_{4}$ sprayed $\mathrm{TiO}_{2}$ on silicon wafer are shown for $10 \mathrm{kPa}$ and $200 \mathrm{kPa}$ shaping pressures, respectively. Close inspection of these images demonstrate that the higher pressure facilitates a slightly more macroscopically homogeneous $\mathrm{TiO}_{2}$ film. This is further validated through spectroscopic ellipsometry thickness mapping, which shows slightly larger features on the surface of the $10 \mathrm{kPa}$ sample (Figure $6 \mathrm{c}$ ) and an overall standard deviation in thickness of $0.7 \mathrm{~nm}$ compared to only $0.4 \mathrm{~nm}$ for the $200 \mathrm{kPa}$ (figure $6 \mathrm{~d}$ ). More prominent 
structural variations are observed at the microscopic level across these samples, with atomic force microscopy (AFM) topographic images shown in Figure 6c,d for the $10 \mathrm{kPa}$ and $200 \mathrm{kPa}$ samples, respectively. It is evident that the surfaces of the $10 \mathrm{kPa}$ sample possess significant nanoscale pertubations compared to the $200 \mathrm{kPa}$ sample (Figure $6 \mathrm{~g}, \mathrm{~h}$ ).

Evidently, the low pressure deposition conditions cause larger $\mathrm{TiO}_{2}$ coating variations compared to the higher pressure deposition both at the macro and micro levels. This observation is likely to arise directly from the lower droplet and impact velocities, which are critical parameters for depositing volatile droplets onto high-temperature substrates. If the droplets being deposited prematurely evaporate to a point where decomposition is occurring during the droplet flight and/or they do not coalescence on the substrate following impact, then an inhomogenous coating will be observed.$^{38}$ Fortunately, the TAA solution thermalizes relatively slowly compared to the carrier solvent (IPA), which makes variations moderate and prevents dry powder deposition under our experimental conditions, but noticeable differences are observed nonetheless because this balance isn't achieved at the lower shaping pressure.

To understand the relative impact of these structural variations using ultrasonic spray deposition to that for $\mathrm{TiO}_{2}$ deposited through the traditional hand-spray system, we have fabricated batches of PSCs using the entire $100 \mathrm{~cm}^{2} \mathrm{TiO}_{2}$ coated FTO/Glass substrates cut to $1.25 \times 2 \mathrm{~cm}^{2}$ sizes. The extracted device characteristics of these samples without any sample discrimination within a batch are shown in Figure 7. A comparison between the planar device characteristics of hand-spray, 10 $\mathrm{kPa}$ and $200 \mathrm{kPa}$ samples clearly indicates the superior performance of the $200 \mathrm{kPa}$ ultrasonic deposited $\mathrm{TiO}_{2}$ across all device characteristics. Importantly, the hand-spray samples exhibit a relatively high median efficiency of $14.5 \%$, but have a large device performance spread with a standard deviation of $4.6 \%$. In comparison, the $200 \mathrm{kPa}$ sample exhibit a median efficiency of 
$15.6 \%$, albeit with a drastically reduced standard deviation of $1.5 \%$. This indicates that the handspray can provide high quality blocking layers suitable for high-efficiency PSCs, but due to homogeneity problems, there are many poor performing devices. Somewhat surprisingly, the 10 $\mathrm{kPa}$ samples showed the lowest mean performance characteristics, but had comparable standard deviations to the $200 \mathrm{kPa}$. This confirms that the slight differences in macroscopic inhomogeneity of the $\mathrm{TiO} 2$ do not perturb the sample reproducibility over the $100 \mathrm{~cm}^{2}$ deposition scale; however, the topographic variations at the microscopic scale evidently yield poorer hole blocking properties.

To understand if higher levels of reproducibility and device performance could be achieved, we further deposited $\sim 150 \mathrm{~nm}$ thick mesoporous layers of $\mathrm{TiO}_{2}$ on top of $200 \mathrm{kPa}$ sprayed $\mathrm{T}_{4}$ layers prior to the deposition of the perovskite layers. These were deposited by spin-casting using a commercial ink tailored for this deposition approach. This is consistent with the prospects of manufacturing such devices, for which the meso-porous layers would likely be printed, whilst very thin transport layers would in fact be spray deposited. As has been previously suggested, the mesoporous scaffold reduces shunting pathways and enhances electron extraction within perovskite devices. ${ }^{39}$ The device characteristics of the mesoporous PSC devices fabricated here are also shown in Figure 7. It is evident that the presence of the mesoporous layer has a favourable effect on all device characteristics, particularly $\mathrm{J}_{\mathrm{sc}}$ and $\mathrm{FF}$, with the median efficiency being $17.4 \%$. This represents a $12 \%$ relative enhancement compared to the planar device (see in Table 2). Importantly, these enhancements are accompanied by drastic reductions to the absolute standard deviations of all the parameters, with that for efficiency being a remarkable $0.5 \%$. This is direct evidence that the mesoporous layer further assists in creating a more macroscopically homogeneous ETL with more favourable charge extraction properties within this PSC configuration. 


\section{Conclusions}

In this work we have compared the effectiveness of $\mathrm{TiO}_{2}$ layers deposited through the conventional hand-spray and ultrasonic methods as suitable electron transport layers in perovskite solar cells. It was found that hand-spray deposition of $\mathrm{TiO}_{2}$ yields coatings with a macroscopic mean thickness deviation of up to $\pm 15 \%$. This deviation could be significantly reduced to less than $\pm 5 \%$ using ultrasonic deposition. However, this was only achieved when the shaping pressure used during the deposition was high (200 kPa). In comparison, the films deposited at lower pressures (10 kPa) exhibited slightly larger thickness variations and were significantly more inhomogeneous at the microscopic level. These structural variations had a significant effect on the performance of methyl ammonium lead iodide perovskite solar cells, with devices featuring $\mathrm{TiO}_{2}$ deposited using the high shaping pressure ultrasonic approach yielding the highest median efficiency of $15.6 \%$, followed by hand-spray at $14.5 \%$, and finally low shaping pressure ultrasonic method at $11.8 \%$. Importantly, the ultrasonic method yielded devices with a 300\% reduction in standard deviation of efficiency compared to the hand-spray, which can be directly correlated to the macroscopic homogeneity of the $\mathrm{TiO}_{2}$ layers. The inclusion of a mesoporous $\mathrm{TiO}_{2}$ nanoparticle scaffold onto the high shaping pressure $\mathrm{TiO}_{2}$ layers was found to enhance the mean efficiency to $17.4 \%$ and remarkably provide a further $300 \%$ reduction to its standard deviation. These results indicate that the ultrasonic spray method is a suitable approach to fabricating high quality and reproducible $\mathrm{TiO}_{2}$ electron transporting layers for PSC, provided that high deposition pressures are used. Coupling this deposition approach to additional mesoporous layers provides further efficiency and reproducibility benefits, which are important factors towards larger area perovskite device fabrication. 


\section{FIGURES}
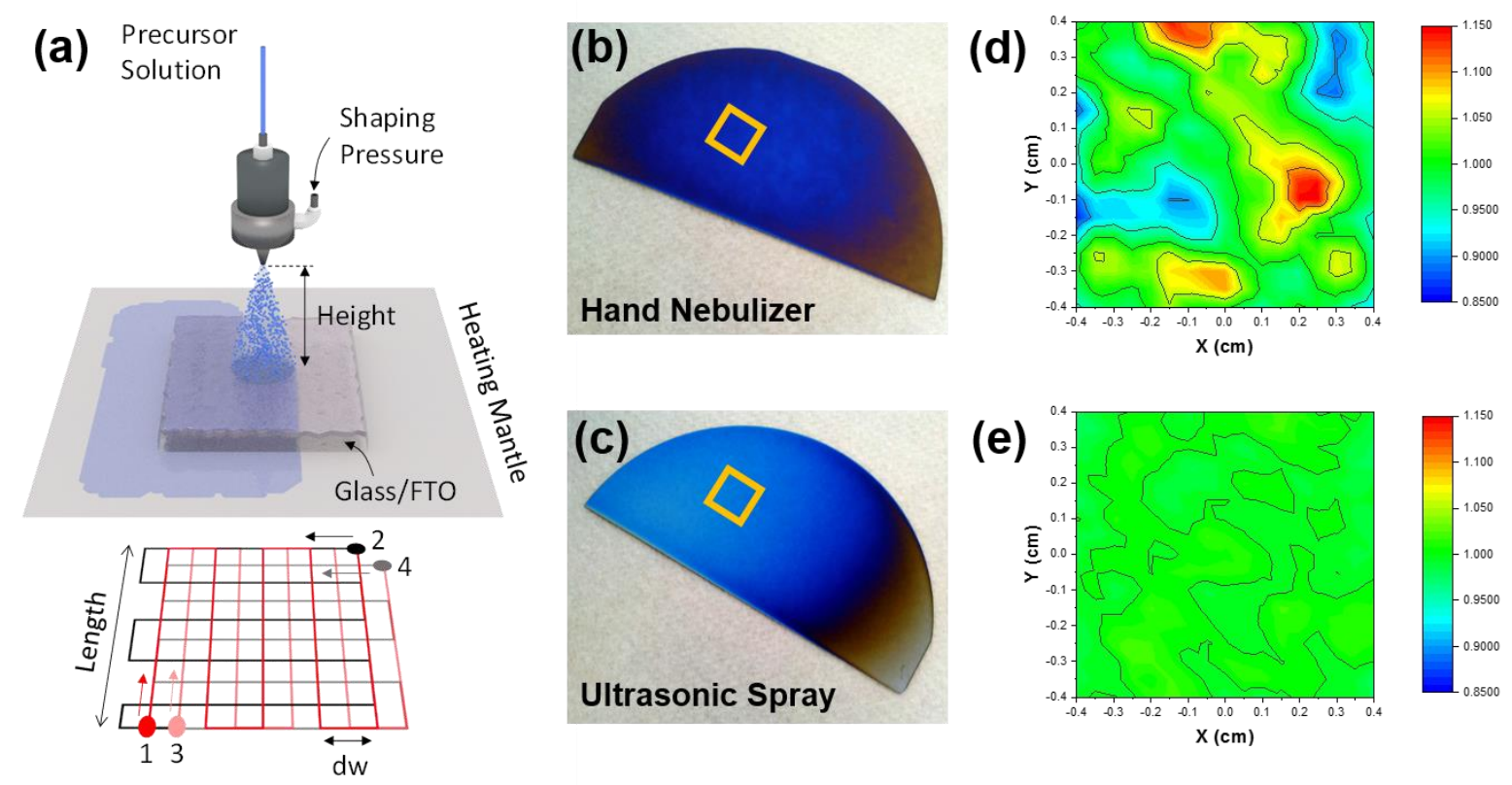

Figure 1. Schematic diagram of the ultrasonic spray deposition approach used in this work (a). Digital photographs and relative thickness maps derived from spectroscopic ellipsometry of marked areas in the micrographs of $\mathrm{TiO}_{2}$ sprayed on silicon wafers by a conventional hand nebulizer (b, d) and through ultrasonic spray deposition (c, e).

(a)

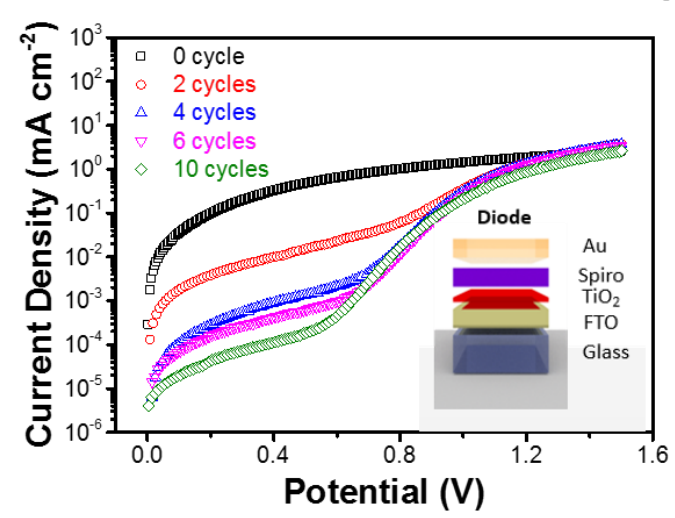

(b)

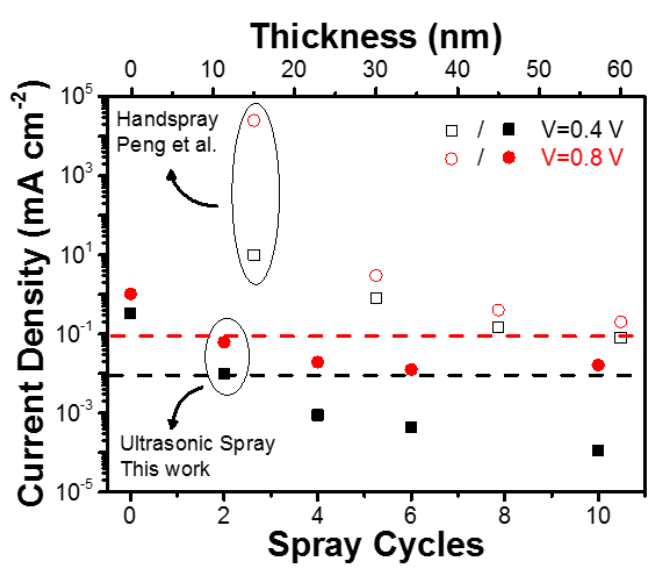

Figure 2. J-V curves of $\mathrm{TiO}_{2}$ layers for increased spraying cycles of $\mathrm{FTO} / \mathrm{TiO}_{2} / \mathrm{Spiro-OMeTED} / \mathrm{Au}$ diodes (a) and specific current values at selected voltages of 0.4 and $0.8 \mathrm{~V}(\mathrm{~b})$. The dashed lines at 0.1 and $0.01 \mathrm{~mA} \mathrm{~cm}^{-2}$ represent the minimum proposed current density requirements at 0.4 and $0.8 \mathrm{~V}$, respectively, for this diode to exhibit sufficient blocking characteristics to be suitable in solar cells, as identified by Peng et al. ${ }^{34}$ 
(a)

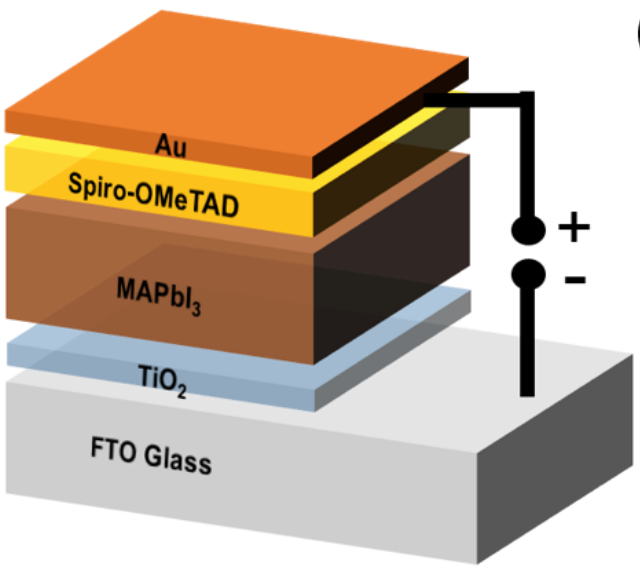

(b)

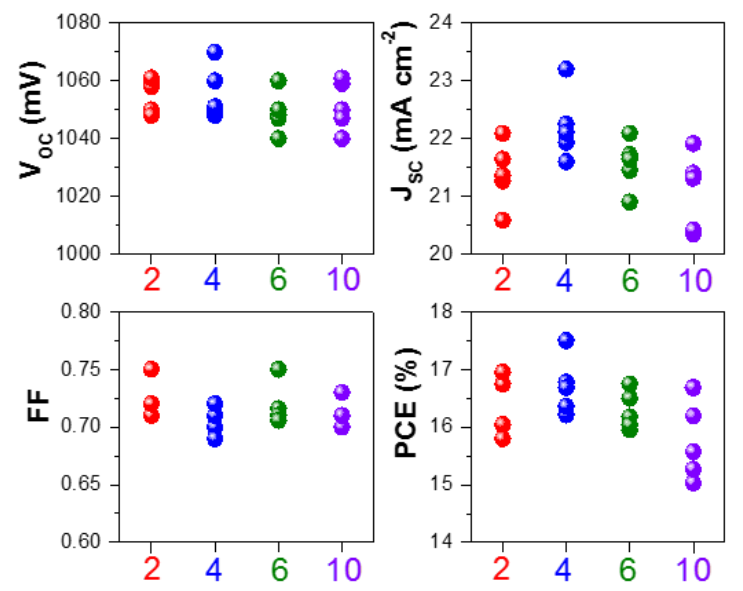

Figure 3. Structural model of perovskite solar cells (a) and summarized parameters of devices using $\mathrm{TiO}_{2}$ layers sprayed by increased cycles (b).

(a)

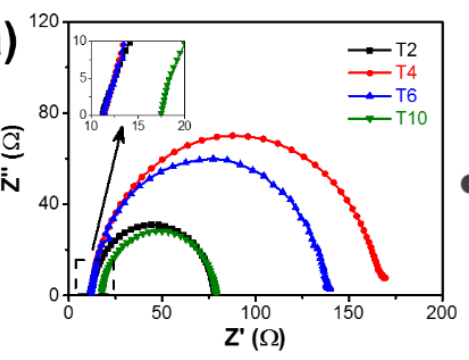

(d)

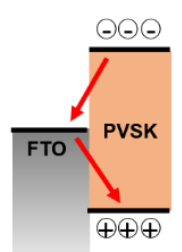

(b)
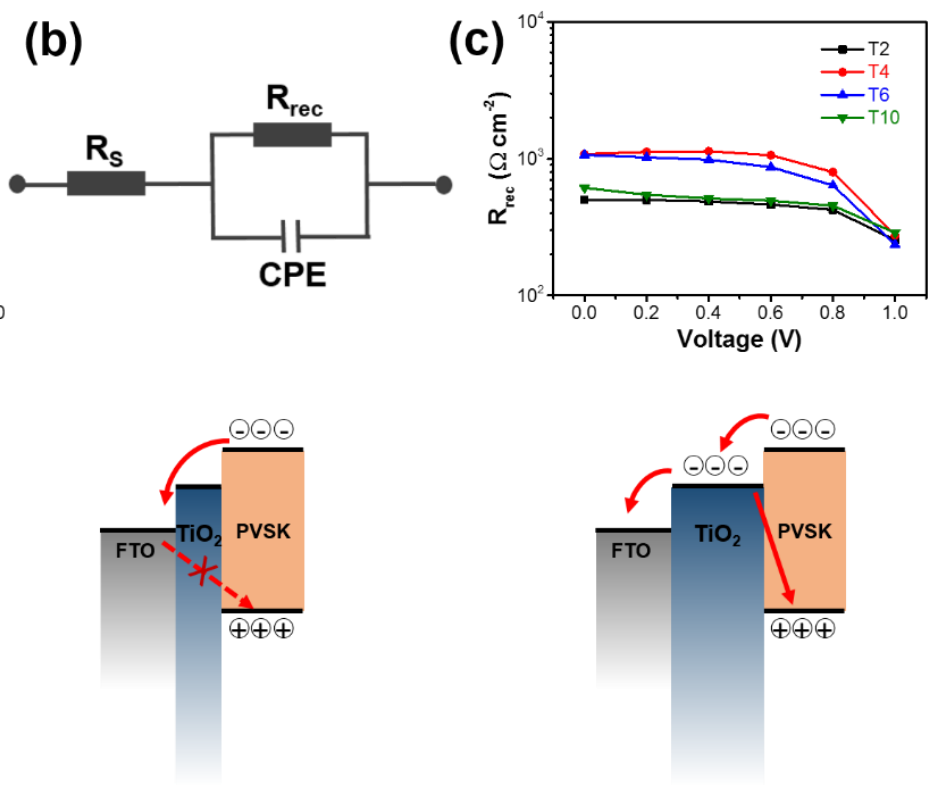

Figure 4. Nyquist plot of perovskite device with $\mathrm{T}_{\mathrm{x}} \mathrm{ETL}$ at a bias of $0.8 \mathrm{~V}$ under 1 sun illumination (a) using the equivalent circuit model $(\mathrm{b})$, recombination resistance $\left(\mathrm{R}_{\mathrm{rec}}\right)$ as the function of the applied voltage at 1 sun illumination (c) and schematic of the proposed carrier extraction and recombination mechanisms at different $\mathrm{TiO}_{2}$-perovskite interface (d). 
(a)

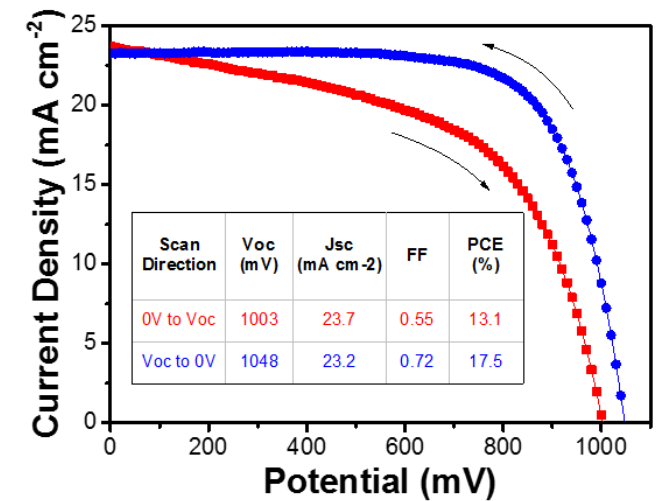

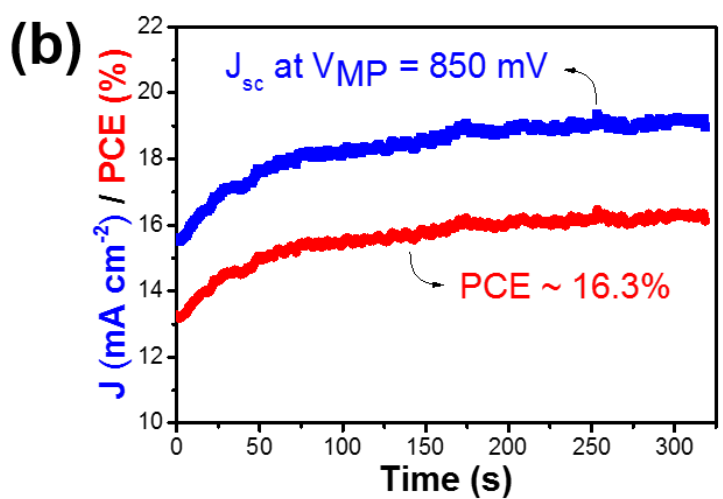

Figure 5. J-V curves (a) and steady state output curves (b) of perovskite solar cell using $\mathrm{TiO}_{2}$ layers sprayed by 4 cycles form forward and reverse scan. 

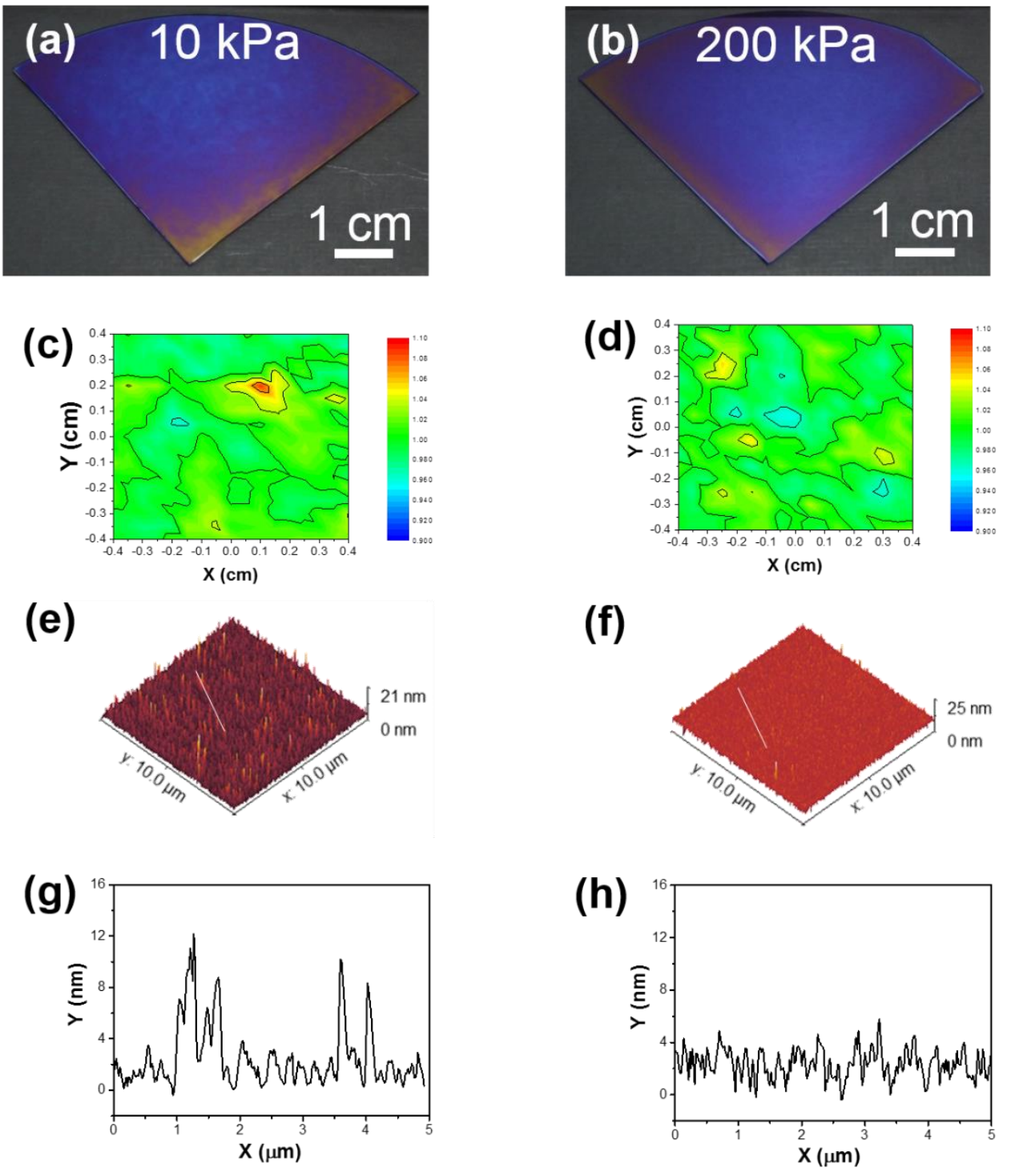

Figure 6. Digital photographs (a, b), spectroscopic ellipsometer thickness maps relative to the median thickness (c, d), 3-dimensional (e, f) and line (g, h) AFM profiles of ultrasonic spray-deposited $\mathrm{TiO}_{2}$ films on silicon wafers with a $10 \mathrm{kPa}$ (top) and $200 \mathrm{kPa}$ (bottom) shaping gas pressure, respectively. 
(a)

(b)
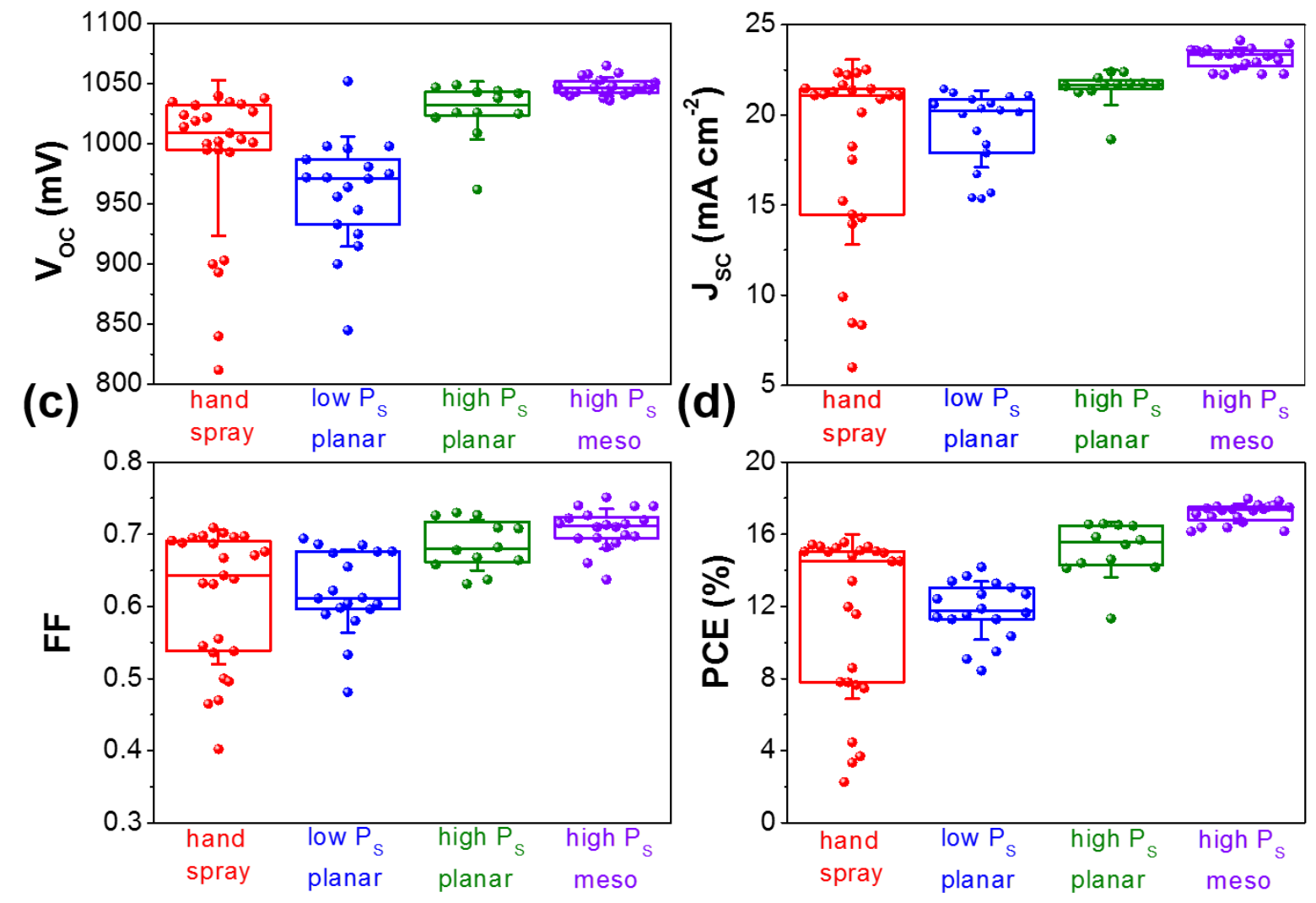

Figure 7. Summary of the perovskite solar cell $\mathrm{V}_{\mathrm{oc}} \mathrm{s}, \mathrm{J}_{\mathrm{sc}} \mathrm{s}, \mathrm{FFs}$ and PCEs (represented in a, b, c and d, respectively) using $\mathrm{TiO}_{2}$ made by hand-spray, ultrasonic spray with low pressure shaping gas, ultrasonic spray with high pressure shaping gas with and without mesoporous $\mathrm{TiO}_{2}$ layer. 


\section{TABLES}

Table 1. Fitted devices parameters of $\mathrm{TiO}_{2} /$ Spiro-OMeTAD diodes using a Schokley model.

\begin{tabular}{ccccc}
\hline $\mathbf{T}_{\mathbf{x}}$ & $\mathbf{R}_{\mathbf{s}}\left(\boldsymbol{\Omega} \mathbf{c m}^{\mathbf{2}}\right)$ & $\mathbf{R}_{\mathbf{s h}}\left(\mathbf{k} \boldsymbol{\Omega} \mathbf{c m}^{\mathbf{2}}\right)$ & $\mathbf{J}_{\mathbf{0}}\left(\mathbf{m A ~ c m} \mathbf{~ m}^{-\mathbf{2}}\right)$ & $\mathbf{n}$ \\
\hline 2 & 7.97 & 4 & $1.22 \times 10^{-5}$ & 3.68 \\
4 & 8.47 & 43 & $1.04 \times 10^{-9}$ & 2.58 \\
6 & 7.81 & 115 & $1.11 \times 10^{-9}$ & 2.72 \\
10 & 10.67 & 667 & $2.86 \times 10^{-9}$ & 2.94 \\
\hline
\end{tabular}

Table 2. Mean and medium parameters for PSC devices using different $\mathrm{TiO}_{2}$ ETLs.

\begin{tabular}{|c|c|c|c|c|}
\hline Samples & $\mathrm{J}_{\mathrm{sc}}\left(\mathrm{mA} \mathrm{cm}^{-2}\right)$ & $\mathbf{V}_{\text {oc }}(\mathbf{m V})$ & FF & PCE (\%) \\
\hline \multirow[t]{2}{*}{ Hand-spray } & $17.95 \pm(5.13)$ & $988.20 \pm(64.55)$ & $0.61 \pm(0.09)$ & $11.43 \pm(4.56)$ \\
\hline & 21.08 & 1009.00 & 0.64 & 14.49 \\
\hline \multirow{2}{*}{$\begin{array}{c}\text { Ultrasonic } \\
\text { spray } \\
(10 \mathrm{kPa})\end{array}$} & $19.23 \pm(2.13)$ & $960.28 \pm(45.70)$ & $0.62 \pm(0.06)$ & $11.76 \pm(1.61)$ \\
\hline & 20.21 & 971.50 & 0.61 & 11.73 \\
\hline \multirow{2}{*}{$\begin{array}{c}\text { Ultrasonic } \\
\text { spray } \\
\text { (200kPa, } \\
\text { planar) }\end{array}$} & $21.52 \pm(0.97)$ & $1027.75 \pm(14.02)$ & $0.67 \pm(0.03)$ & $15.14 \pm(1.54)$ \\
\hline & 21.68 & 1032.00 & 0.68 & 15.56 \\
\hline \multirow{2}{*}{$\begin{array}{l}\text { Ultrasonic } \\
\text { spray } \\
(200 \mathrm{kPa} \\
\text { meso) }\end{array}$} & $23.16 \pm(0.59)$ & $1047.65 \pm(7.56)$ & $0.71 \pm(0.03)$ & $17.16 \pm(0.55)$ \\
\hline & 23.34 & 1046.50 & 0.71 & 17.35 \\
\hline
\end{tabular}




\section{Supporting Information}

The Supporting Information provides thickness maps derived from spectroscopic ellipsometry of $\mathrm{TiO}_{2}$ sprayed on silicon wafers and SEM analysis of $\mathrm{TiO}_{2}$ deposited with different cycle number on FTO.

\section{Author Information \\ Corresponding Author}

*Corresponding author: Jacek.Jasieniak@,monash.edu

\section{Author Contributions}

The manuscript was written through contributions of all authors. All authors have given approval to the final version of the manuscript. $\$$ These authors contributed equally.

\section{Acknowledgment}

JS acknowledges funding support through the Monash Graduate Scholarship and Monash International Postgraduate Research Scholarship programs. JJ acknowledges funding support through the Australian Research Council under the grant CE170100026. The authors acknowledge the use of the facilities at the Monash Centre for Electron Microscopy (MCEM). 


\section{References}

1. Correa-Baena, J.; Saliba, M.; Buonassisi, T.; Grätzel, M.; Abate, A.; Tress, W.; Hagfeldt, A., Promises and Challenges of Perovskite Solar Cells. Science 2017, 358, 739-744.

2. Snaith, H. J., Perovskites: the Emergence of a New Era for Low-cost, High-efficiency Solar Cells. J. Phys. Chem. Lett. 2013, 4, 3623-3630.

3. Akihiro Kojima; Kenjiro Teshima; Yasuo Shirai; Miyasaka, T., Organometal halide perovskites as visible-light sensitizers for photovoltaic cells. J. Am. Chem. Soc. 2009, 131, 60506051.

4. Yang, W.; Park, B.; Jung, E.; Jeon, N.; Kim, Y.; Lee, D.; Shin, S.; Seo, J.; Kim, E.; Noh, J.; S., S., Iodide Management in Formamidinium-lead Halide-based Perovskite Layers for Efficient Solar Cells. Science 2017, 356, 1376-1379.

5. Niu, G.; Guo, X.; Wang, L., Review of Recent Progress in Chemical Stability of Perovskite Solar Cells. J. Mater. Chem. A 2015, 3, 8970-8980.

6. $\quad$ Espinosa, N.; Serrano-Luján, L.; Urbina, A.; Krebs, F. C., Solution and Vapour Deposited Lead Perovskite Solar Cells: Ecotoxicity from a Life Cycle Assessment Perspective. Sol. Energy Mater. Sol. Cells 2015, 137, 303-310.

7. $\quad$ Docampo, P.; Ball, J. M.; Darwich, M.; Eperon, G. E.; Snaith, H. J., Efficient Organometal Trihalide Perovskite Planar-heterojunction Solar Cells on Flexible Polymer Substrates. Nat. Commun. 2013, 4, 2761.

8. Liu, M.; Johnston, M. B.; Snaith, H. J., Efficient Planar Heterojunction Perovskite Solar Cells by Vapour Deposition. Nature 2013, 501, 395-398.

9. Ball, J. M.; Lee, M. M.; Hey, A.; Snaith, H. J., Low-temperature Processed Mesosuperstructured to Thin-film Perovskite Solar Cells. Energy Environ. Sci. 2013, 6, 1739-1743.

10. Kim, H. S.; C. Lee; J. Im; K. Lee; T. Moehl; A. Marchioro; S. Moon; R. Humphry-Baker; J. Yum; J. Moser; M. Gratzel; Park, N., Lead Iodide Perovskite Sensitized All-solid-state Submicron Thin Film Mesoscopic Solar Cell with Efficiency Exceeding 9\%. Sci. Rep. 2012, 2, 591.

11. M. Lee; J. Teuscher; T. Miyasaka; T. N. Murakami; Snaith, H. J., Efficient Hybrid Solar Cells Based on Meso-superstructured Organometal Halide Perovskites. Science 2012, 338, 643647.

12. Chung, I.; Lee, B.; He, J.; Chang, R. P.; Kanatzidis, M. G., All-solid-state Dye-sensitized Solar Cells with High Efficiency. Nature 2012, 485, 486-489.

13. Bach, U.; Lupo, D.; Comte, P.; Moser, J. E.; Weissortel, F.; Salbeck, J.; Spreitzer, H.; Gratzel, M., Solid-state Dye-sensitized Mesoporous TiO2 Solar Cells with High Photon-toelectron Conversion Efficiencies. Nature 1998, 395, 583-585.

14. Moehl, T.; Im, J. H.; Lee, Y. H.; Domanski, K.; Giordano, F.; Zakeeruddin, S. M.; Dar, M. I.; Heiniger, L. P.; Nazeeruddin, M. K.; Park, N. G.; Gratzel, M., Strong Photocurrent Amplification in Perovskite Solar Cells with a Porous TiO2 Blocking Layer under Reverse Bias. J. Phys. Chem. Lett. 2014, 5, 3931-3936.

15. Chandiran, A. K.; Yella, A.; Mayer, M. T.; Gao, P.; Nazeeruddin, M. K.; Gratzel, M., Sub-nanometer Conformal TiO2 Blocking Layer for High Efficiency Solid-state Perovskite Absorber Solar Cells. Adv. Mater. 2014, 26, 4309-4312.

16. Hu, H.; Dong, B.; Hu, H.; Chen, F.; Kong, M.; Zhang, Q.; Luo, T.; Zhao, L.; Guo, Z.; Li, J.; Xu, Z.; Wang, S.; Eder, D.; Wan, L., Atomic Layer Deposition of TiO2 for a High-efficiency 
Hole-blocking Layer in Hole-conductor-free Perovskite Solar Cells Processed in Ambient Air. ACS Appl. Mater. Interfaces 2016, 8, 17999-18005.

17. LadislavKavan, M. G., Highly Efficient Semiconducting TiO2 Photoelectrodes Prepared by Aerosol Pyrolysis. Electrochim. Acta 1995, 40, 643-652.

18. Supasai, T.; Henjongchom, N.; Tang, I. M.; Deng, F.; Rujisamphan, N., Compact Nanostructured TiO2 Deposited by Aerosol Spray Pyrolysis for the Hole-blocking Layer in a CH3NH3PbI3 Perovskite Solar Cell. Solar Energy 2016, 136, 515-524.

19. Kavan, L.; O'Regan, B.; Kay, A.; Grätzel, M., Preparation of TiO2 (anatase) Films on Electrodes by Anodic Oxidative Hydrolysis of TiCl3. J. Electroanal. Chem. 1993, 346, 291-307. 20. Kim, M. C.; Kim, B. J.; Yoon, J.; Lee, J. W.; Suh, D.; Park, N. G.; Choi, M.; Jung, H. S., Electro-spray Deposition of a Mesoporous TiO2 Charge Collection Layer: toward Large Scale and Continuous Production of High Efficiency Perovskite Solar Cells. Nanoscale 2015, 7, 20725-20733.

21. Braga, A.; Baratto, C.; Colombi, P.; Bontempi, E.; Salvinelli, G.; Drera, G.; Sangaletti, L., An Ultrathin TiO2 Blocking Layer on Cd Stannate as Highly Efficient Front Contact for Dyesensitized Solar Cells. Phys Chem Chem Phys 2013, 15, 16812-16818.

22. Ke, W.; Fang, G.; Wang, J.; Qin, P.; Tao, H.; Lei, H.; Liu, Q.; Dai, X.; Zhao, X., Perovskite Solar Cell with an Efficient TiO(2) Compact Film. ACS Appl. Mater. Interfaces 2014, 6, 15959-15965.

23. Xia, J.; Masaki, N.; Jiang, K.; Yanagida, S., Deposition of a Thin Film of TiOx from a Titanium Metal Target as Novel Blocking Layers at Conducting Glass/TiO2 Interfaces in Ionic Liquid Mesoscopic TiO2 Dye-Sensitized Solar Cells. J. Phys. Chem. B 2006, 110, 25222-25228.

24. Acik, I. O.; Madarász, J.; Krunks, M.; Tonsuaadu, K.; Pokol, G.; Niinistö, L., Titanium(IV) aetylacetonate xerogels for processing titania films. J. Therm. Anal. Calorim. 2009, 97, 39-45.

25. Conde-Gallardo, A.; Guerrero, M.; Castillo, N.; Soto, A. B.; Fragoso, R.; CabañasMoreno, J. G., TiO2 Anatase Thin Films Deposited by Spray Pyrolysis of an Aerosol of Titanium Diisopropoxide. Thin Solid Films 2005, 473, 68-73.

26. Wöbkenberg, P. H.; Ishwara, T.; Nelson, J.; Bradley, D. D. C.; Haque, S. A.; Anthopoulos, T. D., TiO2 Thin-film Transistors Fabricated by Spray Pyrolysis. Appl. Phys. Lett. 2010, 96, 082116.

27. Nguyen-Phan, T. D.; Pham, V. H.; Cuong, T. V.; Hahn, S. H.; Kim, E. J.; Chung, J. S.; Hur, S. H.; Shin, E. W., Fabrication of TiO2 Nanostructured Films by Spray Deposition with High Photocatalytic Activity of Methylene Blue. Mater. Lett. 2010, 64, 1387-1390.

28. Arthur H. L; McDonell, V. G., Atomization and sprays, second edition. CRC Press 2017, Second Edition.

29. Mark, B. S.; Henry, C. F., Ultrasonic Deposition of High-Selectivity Nanoporous Carbon Membranes.

30. Bian, J. M.; Li, X. M.; Gao, X. D.; Yu, W. D.; Chen, L. D., Deposition and Electrical Properties of N-In Codopedp-type ZnO Films by Ultrasonic Spray Pyrolysis. Appl. Phys. Lett. 2004, 84, 541-543.

31. Tait, J. G.; Manghooli, S.; Qiu, W.; Rakocevic, L.; Kootstra, L.; Jaysankar, M.; Masse de la Huerta, C. A.; Paetzold, U. W.; Gehlhaar, R.; Cheyns, D.; Heremans, P.; Poortmans, J., Rapid Composition Screening for Perovskite Photovoltaics via Concurrently Pumped Ultrasonic Spray Coating. J. Mater. Chem. A 2016, 4, 3792-3797.

32. Lang, R. J., Ultrasonic Atomization of Liquids. J. Acoust. Soc. Am. 1962, 34, 6-8. 
33. Tachibana, Y.; Umekita, K.; Otsuka, Y.; Kuwabata, S., Performance Improvement of CdS Quantum Dots Sensitized TiO2 Solar Cells by Introducing a Dense TiO2 Blocking Layer. $J$. Phys. D: Appl. Phys. 2008, 41, 102002.

34. Peng, B.; Jungmann, G.; Jäger, C.; Haarer, D.; Schmidt, H. W.; Thelakkat, M., Systematic Investigation of the Role of Compact TiO2 Layer in Solid State Dye-sensitized TiO2 Solar Cells. Coord. Chem. Rev. 2004, 248, 1479-1489.

35. Narushima, S.; Mizoguchi, H.; Shimizu, K.; Ueda, K.; Ohta, H.; Hirano, M.; Kamiya, T.; Hosono, H., A p-Type Amorphous Oxide Semiconductor and Room Temperature Fabrication of Amorphous Oxide p-n Heterojunction Diodes. Adv. Mater. 2003, 15, 1409-1413.

36. Kang, B. S.; Ahn, S.-E.; Lee, M.-J.; Stefanovich, G.; Kim, K. H.; Xianyu, W. X.; Lee, C. B.; Park, Y.; Baek, I. G.; Park, B. H., High-current-density CuOx/InZnOx Thin-film Diodes for Cross-point Memory Applications. Adv. Mater. 2008, 20, 3066-3069.

37. Correa-Baena, J.; Turren-Cruz, S.; Tress, W.; Hagfeldt, A.; Aranda, C.; Shooshtari, L.; Bisquert, J.; Guerrero, A., Changes from Bulk to Surface Recombination Mechanisms between Pristine and Cycled Perovskite Solar Cells. ACS Energy Letters 2017, 2 (3), 8.

38. Ham, E.; Gielis, S.; Bael, M.; Hardy, A., Ultrasonic Spray Deposition of Metal Oxide Films on High Aspect Ratio Microstructures for Three-Dimensional All-Solid-State Li-ion Batteries. ACS Energy Letters 2016, $1,5$.

39. Grätzel, C.; Zakeeruddin, S. M., Recent Trends in Mesoscopic Solar Cells Based on Molecular and Nanopigment Light Harvesters. Mater. Today 2013, 16, 11-18. 


\section{TOC GRAPHIC}

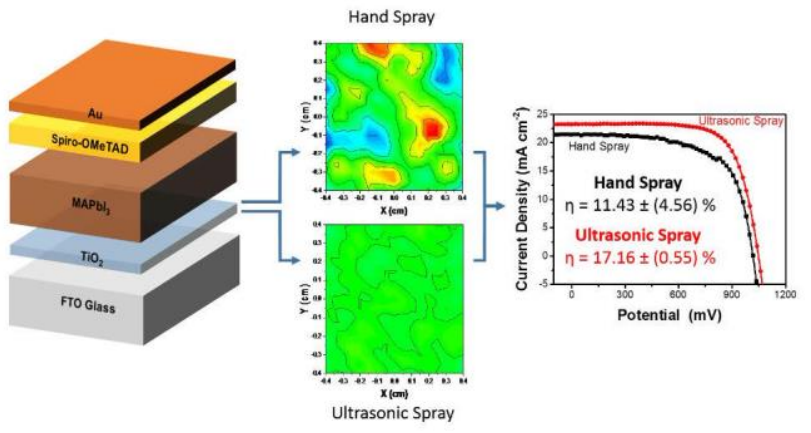

